\title{
Gratifications and Challenges of Banks Adoption of Social Media Advertising Tool
}

\author{
Okaiyeto, Simon Ayodele ${ }^{1} \quad$ Alade, Ngbede ${ }^{2} \quad$ Linus, Mun Ngantem ${ }^{2}$ \\ 1.Mass Communication Department, Salem University, Lokoja, Nigeria \\ 2.Mass Communication Department, Taraba State Polytechnic, Suntai, Nigeria
}

\begin{abstract}
The study looks into how Nigerian banks use social media advertising and what they get out of it. The study's objectives were to investigate First Bank Nigeria's social media advertising trends and determine the benefits and drawbacks of using social media advertising. The study used a quantitative and qualitative research design that was based on the diffusion of innovation theory. The study's quantitative component focused on descriptive and inferential analyses of the bank's social media platforms, as well as answers from respondents (bank employees and customers), while the qualitative component focused on a textual analysis of the social media advertisements. First Bank used a number of internet advertising resources, according to the report (social media inclusive). The findings suggest that social media is simple to use and understand, that it attracts customers' attention to products and services, that it provides an instant feedback mechanism, and that it helps the bank save money. Social media has a broad reach, ensures audience target efficiency, and delivers fun. The strength of social media bank adverts is that they encourage practitioners to work more efficiently by providing rapid feedback, having a broad reach, and being simple to use. The issues of trust management, control, technical knowledge, identity management, unrestricted audience, irreversible information, and crisis communications, on the other hand, are challenging for bank social media usage. On the subject of social media issues, banks advertisers are expected to be aware of the areas that may be addressed, such as preventing unethical and anonymous individuals from accessing their platform. Furthermore, only reputable and trustworthy material should be allowed on social media.
\end{abstract}

Keywords: Advertising, Banks, Challenges, Social Media, Uses and Gratifications

DOI: $10.7176 / \mathrm{NMMC} / 98-03$

Publication date:September $30^{\text {th }} 2021$

\section{Introduction}

Media are central to the practice of advertising from the antiquated period to recent time (Broom, 2009). Today, people find themselves surrounded by a variety of media or communication channels. First, there are the traditional media, such as print, radio and television. While these are proven methods of communication, traditional media lack interactive capabilities. Then, there is the Internet, which has dramatically changed the way society operates. The media of each epoch of the society changes the practice of advertising (Dominick, 2009).

The introduction of new methods of communication always modifies how people receive messages and the Internet is no different (National Archives, 2013). Internet revolutionises the way people shop, pays bills, communicate, etc. Almost anything people want to know or do is virtually at their fingertips. A relatively recent aspect of the Internet is social media. With the emergence of social media, such as blogs and social networking sites, the Internet becomes even more interpersonal and a means in which instantaneous communication thrives. These have had a dramatic impact on the day-to-day activities of advertising practice. With each technology there has been much research into their effects and how they can be used to enhance marketing (Hill \& White, 2000; Porter \& Sallot, 2005). The introduction of social media platforms, where networked communities of individuals, groups and organizations communicate online on a one-to-one, one-to-many, or many-to-many basis (Lieuvrow \& Livingstone, 2006), has again transformed advertising practice and has also made way for the adoption of the two-way symmetrical model as a formal definition of best form of advertising in which the advertising interest directly with the customer. These online tools fit in well with ideal advertising strategies that provide conditions necessary for stimulating dialogue and measuring effect immediately. Consequently, some researchers have explored ways in which social media can be used for brand building and reputation management, customer relationship management, market research advertising and PR campaign (Nwaeze, 2015, Hart, 2010)

For example, Bruhn, Schoenmueller and Schäfer's (2012) online-survey of three distinct industries- tourism, telecommunication, and pharmaceuticals- examined the comparative effect of brand communication on brand equity through social media, in contrast to traditional media. They found that communication by organizations through social media affected brand perception significantly. Undoubtedly, branding has implications on customer relationship management, and scholars have attempted to explore how social media can be used in managing relationships with customers. Regarding customer relationship management, Baird and Parasnis (2011) 
carried out two online surveys, firstly with 1,056 customers in America, Europe and Asia, and secondly on 351 business executives in similar locations. From their findings, they argued that organizations that embrace a more social form of customer relationship management are likely to create increasingly cooperative and valuable experiences with customers.

Since the introduction of Facebook and Twitter, a growing number of commercial organisations (banks) are embracing them as part of their marketing strategy. They have seemingly discovered the potential of the social media in promoting customer relations and increasing product patronage. Despite the merits of the new media over traditional media, scholars still believe it has some challenges that still make traditional media the best source of information. Anthony and Ogidi (2016) also criticise that the new media does not have credibility especially in terms of how they are being accessed and used, they cannot be subjected to any form of check and censorship, as traditional media is checked and censored. Among that challenges of social media to organizations that adopt it, Okaiyeto and Ottah (2021) study found that the issue of trust, identity, control, technical knowledge and crisis control are hampering the successful integration of social media in professionalism. This means that the contents of the new media not being able to be regulated makes it really hard for information on it to be regarded as authentic as anybody that has internet access can decide to upload content on it without any regulation body checking such contents.

In highlighting the merits of traditional media over new media, both scholars explained further that on the other hand, the traditional media has since inception played pivotal roles in the global polity as they help to gather, collate, frame and disseminate news and information contents to the masses wherever they might be for as long as the medium's signal is available (Anthony \& Ogidi, 2016). Also, because of the traditional media's accessibility, advertisers have continued to patronize it for the placement of their marketing and advertisement messages. The essence has been to reach as many consumers as possible and within the shortest time frame. Radio, television and newspapers, among others have been the traditional media platforms that have been engaged by marketers and advertisers to get the far-flung heterogeneous mass audience informed about their various goods and services. This means traditional media will always be reckoned with no matter the level of advancement in technology, this is as a result of the success advertisers have been able to achieve with it in terms of the results of their campaign.

Nevertheless, as social media continues to grow in usage, studies that explore the application of social media for organizational-advertising remain scanty (Nyekwere, Kur \& Nyekwere, 2013; Oluwatolani, Joshua \& Philip, 2011). Also, the use of social media platforms, particularly Facebook, Twitter and Instagram as a tool for advertising and how these relationships are evaluated seem hazy, as most organizations underutilize the technology (Lovejoy, Waters \& Saxton, 2012) especially in the Nigerian context.

New media have so many roles in the banking industries, not only the banking industry but in every organization, which allows easy relationship between the customers to the organization and the organization itself, it also help to facilitate the productivity capacity of the organization.

Being that social media are a new form of advertising platforms and are still evolving in Nigeria, it is unknown on the level at which First Bank is using social media advertising and the effectiveness of adopting the medium for advertising. The general objective of this study is to investigate the uses of social media advertising by First Bank of Nigeria. The specific objectives of the study include: To investigate the patterns of social media advertising by First Bank Nigeria; To examine the gratifications derived from using social media for advertising by First Bank; and to find out the challenges of social media advertising by Banks.

\section{Literature Review}

Few studies have been done in Africa on banks embracing social media advertising ( Adeola, 2016; Eleboda and Majekodunmi, 2015; Oluwatolani, Joshua \& Philip, 2011 ), but more studies have been done in Europe, America, and Asia on the subject (Chanda \& Zaorski, 2013; Veenswyk, 2013). Veenswyk (2013) also indicated that banks are taking advantage of social media's possibilities.

Chanda and Zaorski (2013) investigate the use of social media in the financial services industry from a conceptual standpoint. They noted that the financial services industry uses social media extensively, and that this trend is likely to continue as social networks expand and become more established in the public's online consciousness. However, due to regulatory worries, the industry has lagged behind its corporate colleagues. Regulatory concerns or uncertainty, in the authors' opinion, should not lead to paralysis, but rather should be considered in the context of a financial services firm's intended use of social media. Companies that have a defined business goal in mind will not only be more productive in their online interactions, but they will also be more aware of the hazards. The authors outline four primary reasons why financial services organizations might use social media, as well as the challenges to be aware of and potential pitfalls to avoid.

The study by Nyekwere, Kur, and Nyekwere (2013) looked into citizens of Port Harcourt, Nigeria's awareness and use of social media in advertising. Despite the difficulties associated with its utilization, they discovered that social media is a good medium for advertising. It was also shown that customers buy 
items/services offered on social media primarily because of recommendations/referrals from trustworthy sources - their friends - and because their necessity for such products dictated their purchase.

Adeola (2016), on the other hand, investigates whether the new media marketing notion as a new business philosophy has been successfully applied in the banking industry. The research is based on data acquired from both primary and secondary sources. The study's sample is derived from First Bank of Nigeria. The chi-square method of data analysis was used to analyze the data for the study. According to the findings of the study, marketing activities have played a significant part in the financial sector's development endeavor.

Eleboda and Majekodunmi (2015) analyze the increased adoption of social media advertising among financial services providers, notably banks, in Nigeria, which is closely related to this study. They highlighted that social media advertising has gained traction as a tool for reaching out to the society's "computer-savvy" youth. As a relatively new marketing tool, it has provided businesses with a platform that allows them to better understand and communicate with their customers and prospects in ways that were previously impossible. That it has acquired traction as a tool for reaching out to society's "computer-savvy" youth. As a relatively new marketing tool, it has provided businesses with a platform that allows them to better understand and communicate with their customers and prospects in ways that were previously impossible. Due to young people's great capacity to discern and reject marketing messages that lack credibility, the youth market is considered as a challenging demographic to connect with and sell to, as proven in the literature. A self-administered questionnaire was used to obtain primary data for the study. Using a multistage selection technique, a random sample of 110 respondents, mostly students, was recruited from six higher institutions in Nigeria's Ogun State. Only $93(84.5 \%)$ of the 110 copies of the questionnaire issued were returned. The data was examined using descriptive and inferential statistics, as well as regression analysis. The findings suggest that SMA has an impact on youth shopping behavior, including liking, interest, and actual purchases. This means that Nigerian youths are responding to SMA and will likely respond even more strongly in the future, as the coefficient of youth buying behavior is 2.31 (P0.05), implying that every unit of SMA effort will result in a 2.31 unit change in youth buying behavior, all other factors being equal.

It is clear from the above assessment that there is a substantial quantity of material on the subject of banks embracing news media. However, most of the existing bank research on social media advertising concentrated on Western countries, presumably because they dominate the global media scene; however, Asian countries are beginning to provide studies. African studies (Nigeria) are a relatively new development. However, as evidenced by the research, scholars agree that social media advertising is gaining center stage in marketing. While the findings of these studies show that banks are increasingly adopting social media advertising, there are only a few skeletal sources in the existing literature on the use of social media advertising by old generation banks like First Bank, confirming the analytical gap that this study aims to fill.

\section{Theoretical Framework}

This research is based on the notion of Uses and Gratification. Elihu Katz, Jay Blumler, and Michael Gurevitch first proposed the Uses and Gratification Theory in 1974. "The idea was established to explain why viewers actively and purposefully seek out kinds of content that give them with information that they need, like, and utilize, rather than passively waiting for media messages to arrive" ( Kur, 2003, p.34). According to Folarin $(2005$, p. 65$)$, the theory views the recipient of media messages as actively influencing the effect process; he selects, attends to, perceives, and retains media messages based on his wants and beliefs. This means that "members of the public will actively select and employ specific forms of media content to fulfill their wants and give gratifications of their interests and reasons" (Defleur \& Dennis) (1994, p. 559).

The media consumer's point of view is taken into account in the uses and gratifications standpoint. It investigates how people utilize the media, as well as the enjoyment they seek and receive from it. Audience members are aware of and can express their motivations for consuming diverse media information, according to the uses and gratifications researchers (Wimmer \& Dominick 2014, p. 403).

As a result, when used in this study, social media allows for involvement because it allows advertisers and customers to communicate with one another on a one-on-one basis. The assumption is that banks that use social media are active because they build a Facebook page or a Twitter account of their own volition. Rather than relying on other sources, the banks choose to use social media to achieve their objectives. Basically, the banks create a Facebook or Twitter account for a specific purpose. That is, the requirement to communicate with customers in order to market a product or service. For other users, it could be a want to interact interpersonally with friends, a desire to patronize a product/service advertised on those social platforms, or simply a desire to learn more about an organization they are interested in.

\section{Methodology}

Both a quantitative and qualitative research design was used in this study. The quantitative analysis focused on the descriptive and inferential analysis of the bank's social media platforms as well as replies from respondents 
(bank employees and customers). The qualitative research allows the researcher to describe the types of products First Bank advertises on social media. We looked at the content on First Bank's Twitter, Facebook, and Instagram profiles in Nigeria. The advertising items on the banks' Twitter, Facebook, and Instagram profiles (Content categories: Audio Visuals, Written Texts, and Pictorial Resources) serve as the unit of analysis. For both pilot and final coding, inter-coder reliability was greater than 0.70 . After the pilot test, no items were removed. In the end, each media item from the pilot study was kept for the final study.

In order to complete the survey, letters were addressed to bank managers to obtain an accurate number of bank customers in order to calculate the population for this study, but they were denied on the grounds that such information is confidential and cannot be released. Alternatively, a sample frame was determined by counting the number of staff/customers who came into the banking hall for transactions on the 8th, 12th, 15th, and 19th of March 2019, between the hours of 8 a.m. and 12 noon, at two branches of each selected bank in Ilorin.

Table 1: Sample Frame based on researchers visits to banks

\begin{tabular}{lllrc}
\hline Bank & Branch & Time of visit & No. of bank Staff/Customers & Date \\
\hline FBN & Unilorin & 10 am -12 noon & 73 & Monday $8^{\text {th }}$ \\
FBN & Unity & $8 \mathrm{am}-10$ am & 212 & Friday 19 th \\
Total & & & $\mathbf{2 8 5}$ & \\
\hline
\end{tabular}

Source: Researchers field work 2019

A sample frame was built based on the aforementioned data by observing the average number of clients who visited the bank on the observed days. There were 1191 clients in total in the sampling frame. Based on a 95 percent confidence level and a 0.05 significant level, the total number of customers necessary was 280, according to Krejcie \& Morgan's 2006 Small Sample Technique chart. The questionnaire is divided into three sections: Section 1: this section dealt with the demographic data of the respondents, such as their age, gender, level of education, and bank category. Section 2: this section inquired about the pattern of social media advertising aspects of banks' websites and social networking sites, such as frequency of usage, purpose of use, frequency of visits, and time spent while using. Section 3: this section inquired about the gratification for banks' usage of social media for marketing purposes and Section 4 is all about the challenges banks experience using social media. A reliability test utilizing Cronbach's alpha coefficient indicated a minimum of 0.70 for the scales.

\section{Results}

\section{Demographic Variables of the Respondents}

On the average, the respondents of this study are 30 years old $(\mathrm{M}=30.06, \mathrm{SD}=11.12)$. Those within the age of 18-25 years old form the bulk of the respondents. They account for half $(50.4 \%)$ of the total respondents. This was followed by those between the ages of 26 and 50 years which represents $43.3 \%$ of the respondents and the working class group, while those above 50 years old are the least age group, they represents $6.3 \%$ of the respondents and the elderly. Females represented 54.5 percent of respondents while the other 45.5 percent were males.

\section{Patterns of Social Media Use}

The Content Analysis provide answers to research question one - What are the patterns of advert presented on First Bank Social Networking Sites?

This research questions looks at the advertisement attributes that are present on the banks' social networking sites. First bank's, Twitter, Facebook and Instagram pages were examined. The unit of analysis was Sixteen (16) items which represents media contents of the banks' social media sites. These items are: Adverts and Media, press statement, Video, Audio and Photo gallery, Blog pages, Live chat, Media contact, Download centers, Annual reports, About us section, FAQ, Face Book pages, Instagram pages, Sitemap and Feed bank sections. The items were analyzed for the five areas of social media advertising communication as present or not.

However, the items were re-coded into thematic group consisting of Audiovisuals adverts (daverts, news, audio, video and blogs); Written text Resources (live chat, news, download centre, about us, contact us, FAQ, annual report, feedback, complaint, media centers) and Pictorial Resources (Photos, Face Book post, Instagram posts and sitemaps).

Table 2: Frequency of advertising Resources Commonly used on First Bank Social Networking Sites.

\begin{tabular}{lrr}
\hline Dialogic Resources & Frequency & Percentage \\
\hline Audiovisuals Adverts & 20 & 32.2 \\
Written Text Resources & 12 & 19.4 \\
Pictorial Resources & 30 & 48.4 \\
Total & $\mathbf{6 2}$ & $\mathbf{1 0 0 . 0}$ \\
\hline
\end{tabular}

Source:Researchers field work 2019

Advertising resources are extremely vital for the growth and survival of business organizations in today's competitive world. In the banking sectors, advertisement resources affords bank the opportunity to deliver state 
of the art customer services to its customers while maintain the market competitiveness required for gaining business. Hence, advertising pictorial resources occur the most with $48.4 \%$ which works in line with the principle of usefulness of pictorial element during advertising.

Posted on it Facebook Page (Feb. 27, 107), First Bank attest the important of social media:

In the last few years, First Bank has rolled out some banking and lifestyle digital offerings such as USSD banking service, online and mobile applications to boost convenience and ease of banking for its customers as they are enabled to engage in banking transactions from the comfort of their homes with the FirstMobile app and stay updated on the latest global trend from their mobile phones using the FirstBank LOOP - a lifestyle app. The LOOP app provides premium content from across the world delivered right to mobile phones. Contents include Technology \& Gadgets, The Economy, Luxury Goods, Health, Entertainment, Business, Life \& Travel, Sports, Shopping and more. LOOP ensures that customers are the first to know about the topics and events that matter most to them. FirstBank customers can now enjoy enhanced digital experience just with their mobile phones. With FirstMobile app, customers can conveniently pay bills, buy airtime and do money transfers of up to N500,000 (Five hundred thousand naira to any banks without the need for a token and up to a daily limit of 1 million naira using their mobile phones anywhere, anytime .

Audiovisuals advertising material affords the visitors opportunity to have an in-depth knowledge about the activities of the bank, it products and services occurred second most often at $32.2 \%$, to support this, a study by Efma and Vidyo (2016) found that $70 \%$ of customers prefer video banking on mobiles and desktops over making the journey to a branch, or even simple account and balance enquiries in person at an ATM; as such social media is adding the banks to adverts their online banking. Hence, the use of news and audiovisuals empowers both employees and customers to take matters into their own hands, making banking efficient and easy.

Below is a Facebook Posts on adverts about how digitization could really makes clients banking activities very much convenient:



The influence of social media in marketing and advertising cannot be overemphasized. Financial organizations can use social media as a key component of their customer service initiatives. Research has indicated that social media is the most cost-effective channel for delivering customer service. However, the result shows that selected banks have not fully inputted Social media pictorial advertising resources into their social media sites hence, the low occurrence of $29.3 \%$. First Bank have cease the opportunity social media provides to financial institutions in making banking much efficient and customer's friendly.

\section{Nature of the Advert Message}

Along with the observation of general advertising contents of First bank social media pages(Facebook, Twitter and Instagram). Advertising resources was selected and analyzed for the purpose of investigating the nature of the advert messages. Each media item was coded for "yes" or "no" of the attributes of each of the adverts message pattern. Table 3 presents frequency and percentage of each attribute. 
Table 3: Advert Message Contents

\begin{tabular}{lrrrrrr}
\hline & \multicolumn{2}{c}{ Yes } & \multicolumn{2}{c}{ No } & \multicolumn{2}{c}{ Total } \\
\cline { 2 - 7 } Dialogic Loop & $\mathbf{F}$ & $\mathbf{\%}$ & $\mathbf{F}$ & $\mathbf{\%}$ & $\mathbf{F}$ & $\mathbf{\%}$ \\
\hline Content is a post that doesn't warrant response & 18 & 29.0 & 52 & 71.0 & 62 & 100.0 \\
Content of the item poses a question to stimulate dialogue & 15 & 24.2 & 47 & 75.8 & 62 & 100.0 \\
Content is interactive & 9 & 14.5 & 53 & 85.5 & 62 & 100.0 \\
Request for further comments & 15 & 24.2 & 47 & 75.8 & 62 & 100.0 \\
Direct response to question or comment & 10 & 16.1 & 44 & 83.9 & 54 & 100.0
\end{tabular}

Source: Researchers field work 2019

The attributes of the adverts includes providing customers the opportunity to respond, and then by the organization responding to comments, complaints, and questions. The results as shown above shows that, First bank adverts resources are stimulate dialogue most frequently $(29.0 \%)$, the contents are interactive $(24.2 \%)$. To complete dialogic loop banks request for further comments $(29.0 \%)$ more than giving direct response to question and comments $(14.5 \%)$. The results show that banks are yet to grasp the full impact of interactive adverts in improving bank customers relations

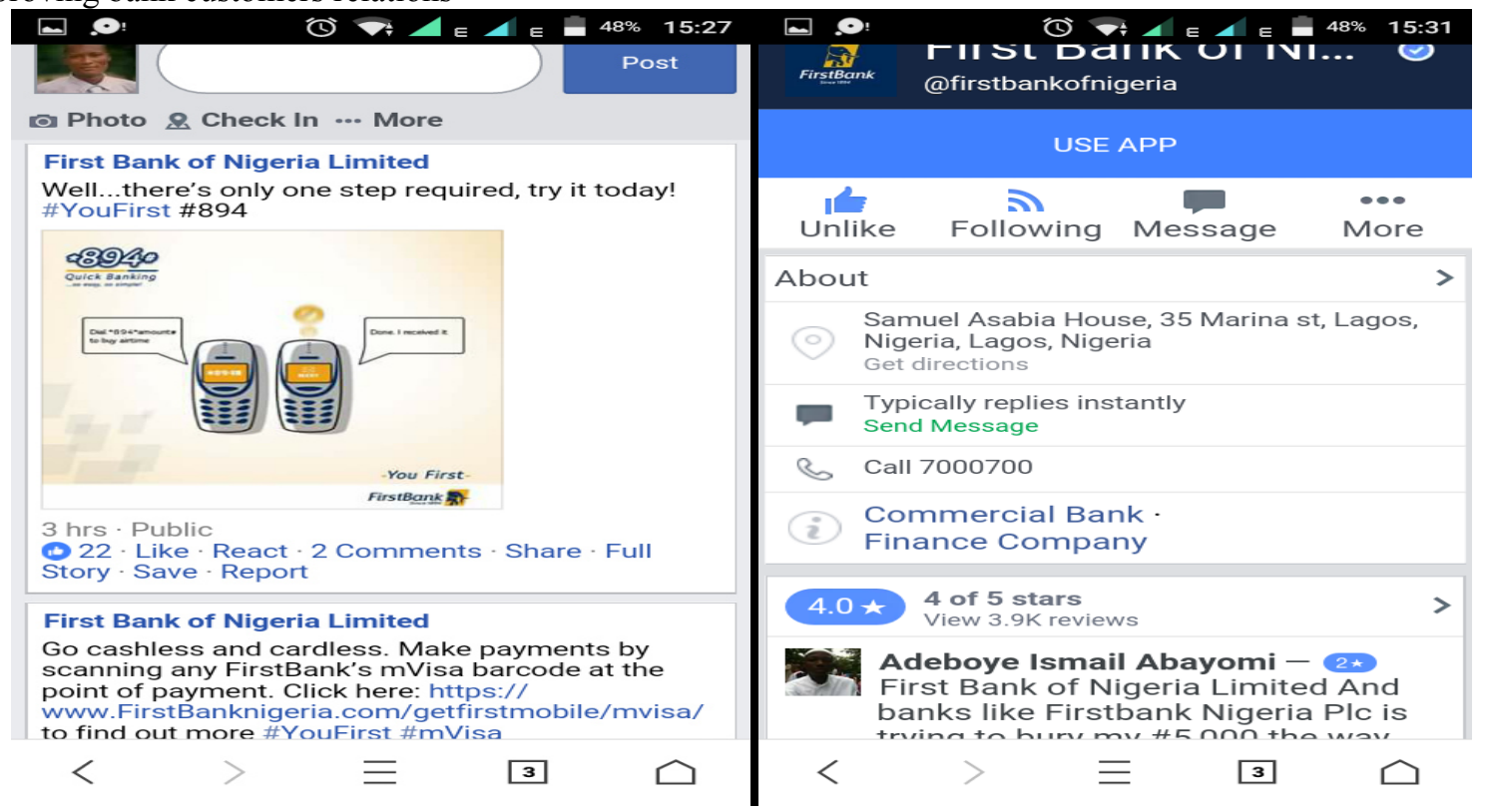

Through post on Facebook and twit on Twitter, First Bank is able to interact with it clients and customers across the world directly. Thus, any new innovation introduced by the bank is brought to the knowledge of the clients. Also, clients are being enlightened through the social media.

Social media enables immediate conversation in real-time. Social media one of the reason why is timeliness, timeliness in essence, as you are doing the programme or activity, immediately you are reaching the target public and immediately your activity is been seen all over the world, so is faster and you don't have to, unlike the mainstream media.

Table 4: Usefulness of Information

\begin{tabular}{lccrrrr}
\hline Usefulness of information & \multicolumn{2}{c}{ Yes } & \multicolumn{2}{c}{ No } & \multicolumn{2}{c}{ Total } \\
\hline Useful to customers and visitors & F & \% & F & \% & F & \% \\
Information on Banks product and services & 56 & 90.3 & 6 & 9.7 & 62 & 100.0 \\
Bank logo & 35 & 56.5 & 27 & 43.5 & 62 & 100.0 \\
Description \& overview of bank & 53 & 85.5 & 9 & 14.5 & 62 & 100.0 \\
Provides persuasive information & 22 & 35.5 & 40 & 35.5 & 62 & 100.0 \\
Item is convincing & 55 & 88.7 & 7 & 11.3 & 62 & 100.0 \\
Marketing a product or service & 57 & 91.3 & 5 & 8.7 & 62 & 100.0 \\
\hline
\end{tabular}

Source: Researchers field work 2019

Social media facilitates First Bank interactive, symmetrical, multi-dimensional dialogue building and managing of relationships with it publics. This study finds that social media have the potentials of speed, interactivity, ubiquity, multimedia advantage and accessibility capacities. Therefore, social media is significantly useful to enhance the practice of advertising in Nigeria financial institution specifically and the world at large 
The principle of usefulness of advertising is meant to provide information to the consumers that will help them answer their questions and make them more informed such as information about products, services, additional items the bank offers is also included in usefulness (Rybalko \& Seltzer 2010). Table 4 presents an analysis of attributes of useful advertising information. Overall, 90.3\% of the information placed on banks website is accessed to be useful to customers and visitors. Other attribute of the usefulness of information includes bank logo which is $85.5 \%$ present. Media contents being analyzed only gives $56.5 \%$ ample information on banks product and services as well as less description and overview of the bank which stands at 35.5\%. For persuasive information, $88.7 \%$ of the adverts messages are meant to convince the customers. Also, the usefulness of the advert is that $96.7 \%$ is meant to market the banks products or services.
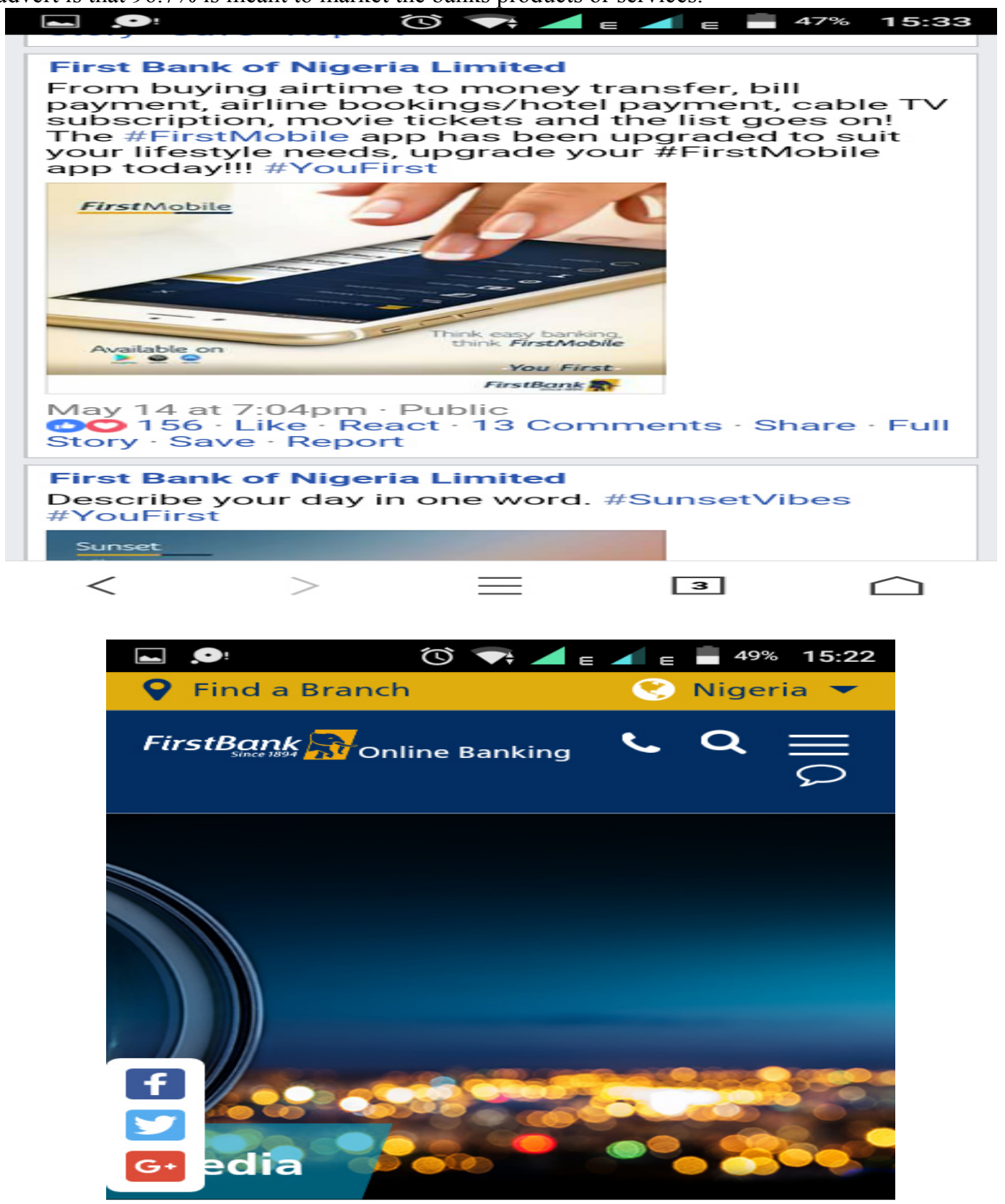

\begin{abstract}
Home $>$ Media
We offer a 24-hour service to the media.

Are vou a iournalist and have media
\end{abstract}

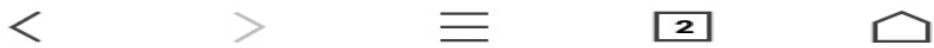

Social media works with speed in terms of immediacy possibility in communication process. With the above post, it is obvious that when the organization send information on the social media, the tendency of getting the feedback immediate is there and that is the benefit. What makes First Bank to offer 24-hour service is 
because of social media speed edge and the ability to work in real-time.

Also, social media is readily accessible to both the bank and it public. Social media is cheap, easy to use and can be access by all with smart phones to even large internet facilitator like ICT. Now With the social media on list of media at audience disposition, the distinguishing feature of new media is interactivity, which describes the ability of users to provide content in response to a source or communication partner (Quan-Haase \& Young, 2010).

Table 5: Generation of Return visits

\begin{tabular}{lrrrrrr}
\hline & \multicolumn{2}{c}{ Yes } & \multicolumn{2}{c}{ No } & \multicolumn{2}{c}{ Total } \\
\cline { 2 - 7 } Generation of Return visits & F & \multicolumn{1}{c}{$\%$} & F & \% & \multicolumn{1}{c}{ F } \\
\hline Users can like, share or comment on post & 19 & 30.6 & 43 & 69.4 & 62 & 100.0 \\
Update information within 30 days & 25 & 40.3 & 37 & 59.7 & 62 & 100.0 \\
Explicit invitation to return & 17 & 27.4 & 45 & 72.6 & 62 & 100.0 \\
Contest and games & 6 & 9.7 & 56 & 90.3 & 62 & 100.0 \\
\hline
\end{tabular}

Source: Researchers field work 2019

Generation of return visit is another attributes of social media advertisements. Attribute of this principle includes asking customers to "share, like or comment" on post, update of information within 30 days, explicit invitation to customers to return, contest and challenges etc. table $4.4 \mathrm{c}$ shows a very low percentage for contest and games $(9.7 \%)$, explicit invitation to return $(27.4 \%)$, prompt for users to like, share or comment on post is $30.6 \%$ while regular update of information within 30days of post is $40.3 \%$. the result reveals poor use of this dialogic feature. This finding contrasts with the findings of Waters and Tindall (2010) that US churches were able to incorporate dialogic features that encouraged return visits (i.e. encouraging visitors to return, updating news items and providing information about the churches).
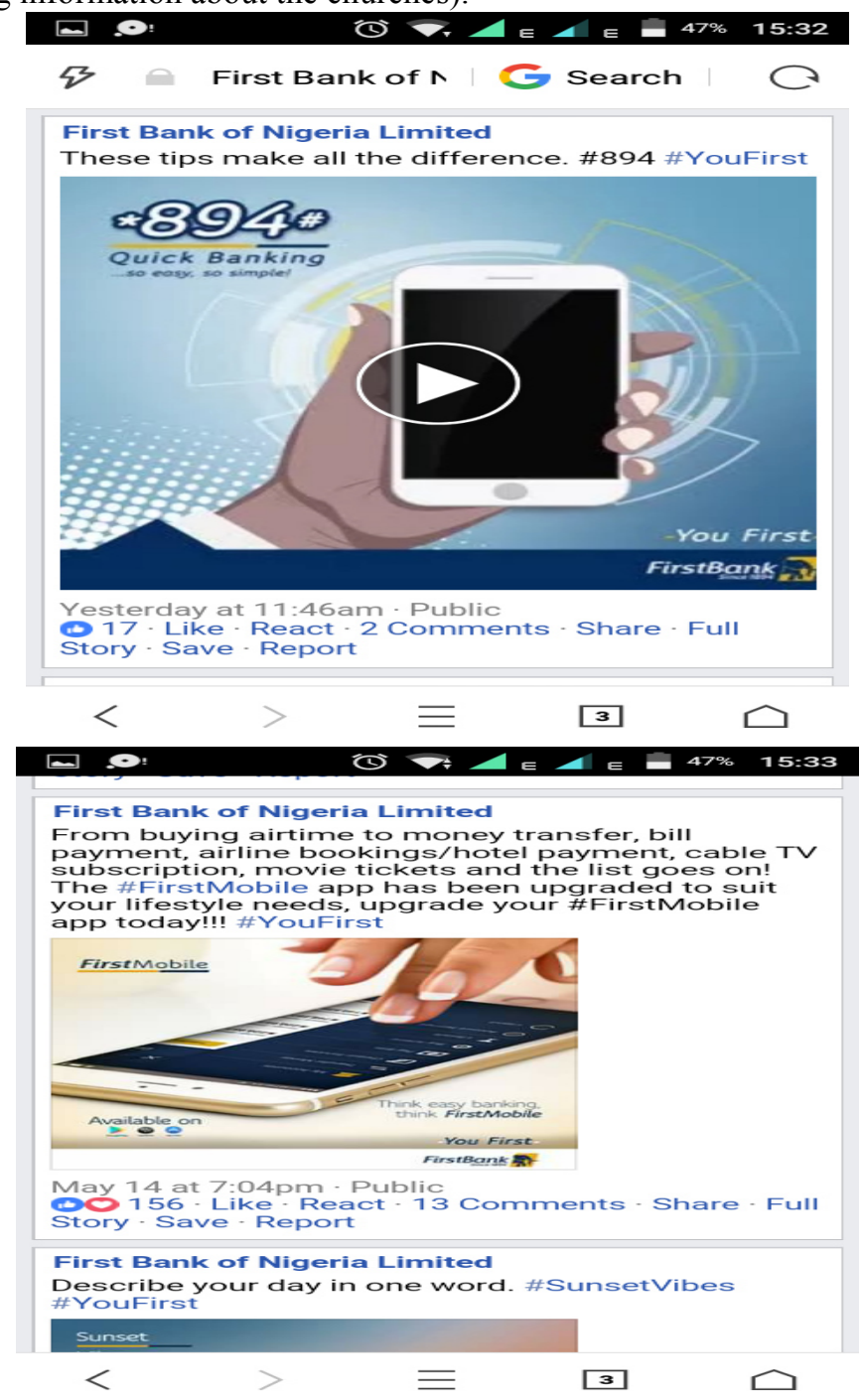

One of the greatest benefits is immediate feedback, immediate feedback and then immediate feedback this immediate feedbacks covers everything one, you know whether your message was important wither message 
was able wither it was efficiently, it gives on the spot feedback which the traditional media cannot.

Timeliness, speed, interactivity and currency as the hallmark of financial institutions engaging on social media use. Thus, social media do connect the organization with the public and the media simultaneously. This will invariably contribute to the organization provision of massages to clarify issues in the eyes of both the public and the media. So, with social media there will be dialogic communication between organization external and internal publics.

Table 6: Conservation of visitors

\begin{tabular}{lcccccc}
\hline & \multicolumn{2}{c}{ Yes } & \multicolumn{2}{c}{ No } & \multicolumn{2}{c}{ Total } \\
\cline { 2 - 7 } Conservation of visitors & F & $\mathbf{\%}$ & F & \% & F & \% \\
\hline Item can be easily downloaded & 29 & 46.8 & 33 & 53.2 & 62 & 100.0 \\
Links to social media pages / websites & 20 & 32.3 & 42 & 67.7 & 62 & 100.0 \\
Public information & 47 & 75.8 & 15 & 24.2 & 62 & 100.0 \\
Link to bank product and services & 42 & 67.7 & 20 & 32.3 & 62 & 100.0 \\
\hline
\end{tabular}

Source: Researchers field work 2019

The fourth social media advertising edge is the conservation of visitors. This attribute was shown within the media resources used by banks on their website and social networking sites allowing the customers to download the content, provide information that is more beneficial to the public, allow links to bank products and providing links to their website or other social media pages. The table above shows that the $75.8 \%$ of information passed by the banks are usually public information. Links to product and services appeared more $(67.7 \%)$ than links to the bank's own website or other social media pages $(32.3 \%)$, media items that can be easily downloaded appeared at $46.8 \%$.

Thus, social media provides lots of information to clients. The post below depict the kind of advertising images First Bank do post on it page.

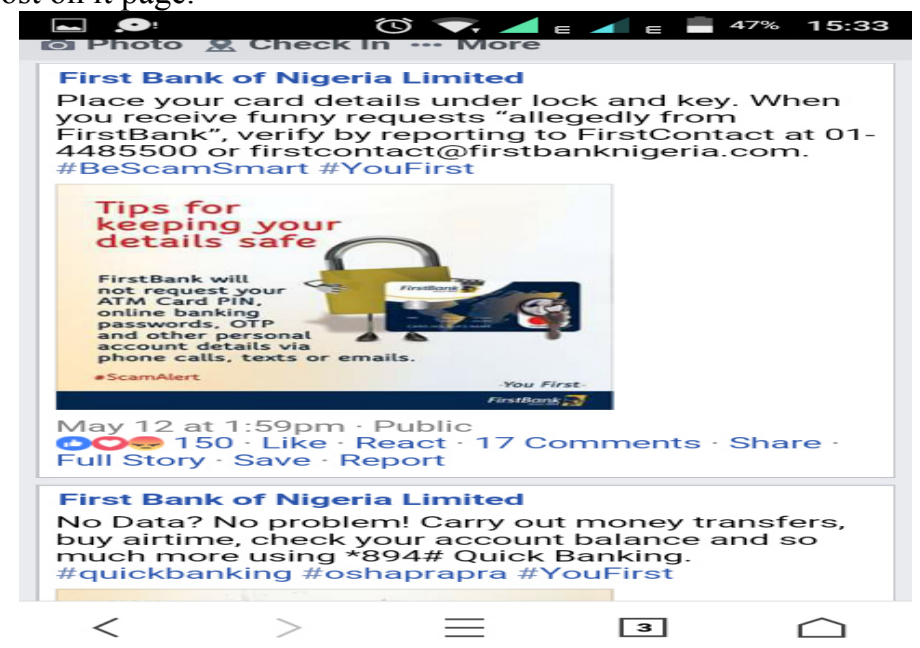

It cost effective to utilize social media for advertising and providing valid information about the bank to the public. To establish social media platform groups in which the Bank will be engaging it public is very cost effect compared to the usual use of mainstream media in the conventional way. To attest this, the post above shows that social media is easy to use, targets more specific audiences, cheaper to use therefore more cost effective compared with mainstream media.

Table 7: Ease of Interface

\begin{tabular}{lcccccc}
\hline & \multicolumn{2}{c}{ Yes } & \multicolumn{2}{c}{ No } & \multicolumn{2}{c}{ Total } \\
\cline { 2 - 7 } Ease of Interface & F & $\mathbf{\%}$ & $\mathbf{F}$ & $\mathbf{\%}$ & F & \% \\
\hline Item is easily accessible & 55 & 88.7 & 7 & 11.3 & 62 & 100.0 \\
Available on the sitemap & 53 & 85.5 & 9 & 14.5 & 62 & 100.0 \\
Graphic reliance & 35 & 56.5 & 27 & 43.5 & 62 & 100.0 \\
Visible Navigation & 15 & 24.2 & 47 & 75.8 & 62 & 100.0 \\
\hline
\end{tabular}

Source: Researchers field work 2019

In regard to the ease of interface principle, $88.7 \%$ of the items are easily accessible customers while $85.5 \%$ of the items are available on the sitemap. Over half of the media Resource contents $(56.5 \%)$ are graphic reliance and only $24.2 \%$ of the items contain visible navigation. This show that attribute of ease of interface are very well pronounced in First Bank social media sites. The features make it easier for visitors to surf around the website. This confirms the findings of Cho and Huh (2010) on user-friendly features of corporate blogs enabling easy navigation. 
Survey was used to answer Research Question Two - What are the gratifications derived from using social media for advertising by First Bank? The objective was to know the benefits First Bank derived from social media advertising. Staff and customers agreed that First Bank use of social networking site for advertising provides the bank with good opportunity to engage with the public positively. Table 8 presents the result Table 8: Gratifications Derived from Social Media Advertising

\begin{tabular}{|c|c|c|c|c|c|c|c|c|}
\hline \multirow[t]{2}{*}{ Gratifications } & \multicolumn{5}{|c|}{ Level of Agreement (\%) } & \multirow[b]{2}{*}{$\mathbf{M}$} & \multirow[b]{2}{*}{ SD } & \multirow{2}{*}{$\begin{array}{l}\text { Over } \\
\text { all } \%\end{array}$} \\
\hline & 1 & 2 & 3 & 4 & 5 & & & \\
\hline Provide instant feedback mechanism & 5.6 & 10.8 & 23.1 & 36.2 & 24.3 & 3.63 & 1.92 & 72.6 \\
\hline Gives provision for banks monitoring trends & 7.5 & 11.6 & 22.0 & 44.8 & 14.2 & 3.47 & 1.10 & 69.4 \\
\hline Wide reach enablement & 5.6 & 10.5 & 22.9 & 39.1 & 21.8 & 3.61 & 1.11 & 72.2 \\
\hline Social media is easy to use and user friendly & 4.9 & 6.0 & 12.3 & 54.5 & 22.4 & 3.84 & 1.00 & 76.8 \\
\hline Draw customers attention to products and services & 6.3 & 6.7 & 27.3 & 39.0 & 20.6 & 3.61 & 1.08 & 72.2 \\
\hline Ensure audience target efficiency & 5.7 & 9.4 & 34.0 & 35.8 & 15.1 & 3.45 & 1.04 & 69.0 \\
\hline Social media promote cost effectiveness for the bank & 4.1 & 6.4 & 25.1 & 50.2 & 14.2 & 3.64 & 0.95 & 72.8 \\
\hline $\begin{array}{l}\text { Social media advert provide source of entertainment to } \\
\text { customers }\end{array}$ & 14.9 & 13.8 & 29.1 & 34.3 & 7.8 & 3.06 & 1.18 & 61.2 \\
\hline Total & & & & & & 3.63 & 1.24 & 72.6 \\
\hline
\end{tabular}

Source:Researchers field work 2019

*Scale: $1=$ Strongly Disagree, $\quad 2=$ Disagree, $\quad 3=$ Slightly Agree, $\quad 4=$ Agree,$\quad 5=$ Strongly Agree
$(1-20 \%)$
$(21-40 \%)$
$(41-60 \%)$
$(61-80 \%)$
$(81-100 \%)$

Overall respondent perceived the bank adverts on social media sites as being beneficial $(\mathrm{M}=3.63, \mathrm{SD}=$ 1.24). The potential of advertising is the extent information appeals to stakeholders and wider customers. In the hopes to fulfill their information needs and information seeking habits, the following features were observed on the study banks' social media pages; direct links to the organizations official website and other social media pages, visible pictures, photos, videos, information on banks product and service and overview of the bank. Results from table 4.6 shows that social media is easy to use and user friendly $(\mathrm{M}=3.84, \mathrm{SD}=1.00)$; draw customers attention to products and services $(\mathrm{M}=3.61, \mathrm{SD}=1.08)$; Provide instant feedback mechanism $(\mathrm{M}=3.63$, $\mathrm{SD}=1.92)$ as well as media promote cost effectiveness for the bank $(\mathrm{M}=3.64, \mathrm{SD}=1.10)$. Also features it provides wide reach enablement $(\mathrm{M}=3.61, \mathrm{SD}=1.11)$ and are fully utilized. It is worth noting that utilization of social media is cost effective for the bank and customers $(\mathrm{M}=3.59, \mathrm{SD}=1.05)$, ensures audience target efficiency $(\mathrm{M}=3.45, \mathrm{SD}=1.04)$ as it equally provide source of entertainment to customers $(\mathrm{M}=3.06, \mathrm{SD}=1.18)$.

Lee (2014) says that social media are also attractive to advertisers because of the relatively low cost of reaching consumers, the potential for greater efficiency, and the ability to engage in more timely and directcontact communication than is offered by most traditional media tools (Choi, 2011; Muntinga et al, 2011).

Social media advertising usually centre on efforts to create content that attracts attention and encourages readers to share it with their social networks. As Corruthers, (2010) pointed out that A corporate message spreads from user to user and presumably resonates because it is coming from a trusted source, as opposed to the brand or company itself. Social media have become a platform that is easily accessible to anyone with Internet access, opening doors for organisations to increase their brand awareness and facilitate conversations with the customer.

Table 9: Pearson's Correlation between Patterns motives for social media advertising and gratifications from social media advertising

Motives for social media adverts \&

Gratifications from social media adverts

\begin{tabular}{ccc}
\multicolumn{3}{c}{ Correlations } \\
\hline $\boldsymbol{r}$ & $\mathbf{N}$ & $\mathbf{P}$ \\
\hline .528 & 246 & .000
\end{tabular}

Source:Researchers field work 2018

The result of Pearson Movement Correlation Coefficient (PMCC) for the two variables (Motives for social media advertising and gratifications form social media advertising) reveals positive and significant relationship $(r=.528, \mathrm{~N}=246, \mathrm{p}=.000)$.

This result is in congruence with Veenswyk (2013) study which identifies that banks are leveraging on the potentials of social media for advertising their products and services and also connecting directly in real-time with their customers. Hence, First Bank social media advertising have significant positive relationship with gratification derived from social media advertising

Research Question Three - What are the challenges of social media advertising by First Bank Nigeria? The objective is to point out the possible challenges the new advertising innovation is posing for banks as they adopt social media for their advertising. Lee (2014) study found that engaging with the public is a major challenge in social media advertising. This study also enumerated staff and customers perception on the challenges of social 
media advertising as the result is presented in table 10 .

Table 10. Challenges of Social Media Advertising for Bank

\begin{tabular}{|c|c|c|c|c|c|c|c|c|}
\hline \multirow[t]{2}{*}{ Challenges } & \multicolumn{5}{|c|}{ Level of Agreement (\%) } & \multirow[b]{2}{*}{$\mathbf{M}$} & \multirow[b]{2}{*}{ SD } & \multirow{2}{*}{$\begin{array}{l}\text { Over } \\
\text { All }\end{array}$} \\
\hline & & 2 & 3 & 4 & 5 & & & \\
\hline Accessibility & 25.0 & 25.4 & 24.3 & 14.6 & 10.8 & 2.61 & 1.30 & 52.2 \\
\hline Unrestricted audience & 15.0 & 17.6 & 23.6 & 30.0 & 13.9 & 3.10 & 1.28 & 62.0 \\
\hline Control of the platform & 11.9 & 17.5 & 19.4 & 31.3 & 19.8 & 3.29 & 1.30 & 65.8 \\
\hline Irreversible information & 17.5 & 16.8 & 22.0 & 30.2 & 13.4 & 3.05 & 1.31 & 61.0 \\
\hline Fragmentation of customers & 26.1 & 20.5 & 23.5 & 20.1 & 9.7 & 2.67 & 1.32 & 52.2 \\
\hline Total & & & & & & 2.94 & 1.30 & 58.8 \\
\hline
\end{tabular}

Source: Researchers field work 2019

* Scale: $1=$ Very Little, $\quad 2=\mathrm{A}$ Little (1-20\%) $(21-40 \%)$

3=Somewhat Much, $(41-60 \%)$

\section{4=Much,}

$(61-80 \%)$

\section{$5=$ Very much} $(81-100 \%)$

From the above result, the two statements that recorded low scores are accessibility of banks social media sites $(\mathrm{M}=2.61, \mathrm{SD}=1.30)$ and fragmentation of customers which makes ability to control and modify the form of content of interaction in real $(\mathrm{M}=2.67, \mathrm{SD}=1.32)$. The implication of these is that, customers are allowed access, only to few items that can be modified on the Banks website or social media pages, for the most part, the layout and design of the pages are limited to small modifications. However, it is certain that control of social media is difficult $(\mathrm{M}=3.29, \mathrm{SD}=1.30)$, Also, audience of social media are unrestricted $(\mathrm{M}=3.10,1.28)$ and irreversible information $(\mathrm{M}=3.05, \mathrm{SD}=1.31)$. Overall, there is an agreement level of $(\mathrm{M}=2.94, \mathrm{SD}=1.30)$ which means that there are challenges in the use of social media for advertising by banks.

The negative aspect of social media has been a challenge to advertisers, especially when it comes to the issue of controlling the unrestricted flow of audience. Also, another issue is the issue of irreversible information. Any posted comment will go viral in a click. Informant 3 a staff captures it:

Negative aspect right now is not regulated recently you see an increased in fake news, it has become something like trauma to the social media so there is no control yet, there is no universal mechanism controlling social media so people are able to dis-inform people, they are able to mail in people, they are able to slander people and so on and so forth, and to propagates fake or inaugurate news, as opposed traditional media, when you had a fact technic system is verification you had the gatekeeper the editor who will verify checks and traditional media are controlled by excepting time texted principle of journalism is it fair, is it truthful, is it balance, is it accurate, you know of those who apply social media so this are the disadvantages of social media, lack of control essentially.

Because entering into social media is very easy and flexible, it makes organization to find it difficult in controlling the flow of entering. Sometimes they just have to maintain close group.

One of the major challenges of banks using social media for advertising is the inability to have control. Informants noted that the continues spread of unverified information, slander, deliberate falsehood, hackers which is difficult to control post a serious challenge to banks in managing internal and external crisis.

Respondents have observed that to identify the original identity of sources of information online is a difficult task for banks social media page managers. This becomes more complicated when it is an anonymous source

As social media exposes banks to internal and external crises; so makes the company finds it difficult in managing crisis. Because of the difficulty in controlling information on social media, managing organization crisis become more difficult. The speed at which information spread online; makes any false or misinformation ideas reach the public in seconds.

Other challenges social media advert brings to banks are: Dealing with Network navy (transparency, disclosure, responsibility) are very hard to achieve on social media, Dealing with hoax information, dealing with unrestricted audience, the issue of immediacy can sometimes be counterproductive, when it comes to managing information. Respondents 16 for instance, illustrate that:

The negative aspect is just the word of mouth, you know when you speak the word, immediately it comes out from your mouth you cannot take it back and the social media is like that once you click and its gone and you just remembered that there's something you need to correct it's gone it might too late, you know and one thing about it is that the traditional media there is that it takes time to run, within that time there might be correction you need to make, you would have make the correction but these one immediately.

Banks have being devising strategies of mitigating the challenges, among which are close monitoring, verification of information, main trust to make sure that unwarranted content are constantly screen out from the social media. 


\section{Discussions}

The gratifications First Bank derived from the use of social media advertising. is beneficial. The potential of advertising is the extent information appeals to stakeholders and wider customers. In the hopes to fulfill their information needs and information seeking habits, the following features were observed on the study banks' social media pages; direct links to the organizations official website and other social media pages, visible pictures, photos, videos, information on banks product and service and overview of the bank. Results shows that social media is easy to use and user friendly; draw customers attention to products and services; Provide instant feedback mechanism; as well as media promote cost effectiveness for the bank. Also features it provides wide reach enablement and are fully utilized. It is worth noting that utilization of social media is cost effective for the bank and customers, ensures audience target efficiency as it equally provide source of entertainment to customers. Therefore, the strength of social media banks' advertisements is that is makes practitioners work efficient through instant feedback, wide reach and ease of usage.

Closely related to this study is the work of Eleboda and Majekodunmi (2015) investigates the growing adoption of social media advertising among financial services providers, particularly banks, in Nigeria. They equally found that banks in the country are fastly adopting social media in their operation.

In his empirical findings Lee, (2013) posits that advertising communication is traditionally thought of as being one-way or two-way, but social media platforms allow multiple users to communicate simultaneously in multiple directions as illustrated by the multi-directional communication model. That is, though social networking sites provide organizations with a space to interact with key publics and to allow users to engage with one another on topics of mutual interest; this should provide the ideal conditions necessary for stimulating dialogic communication and facilitates feedback proactive measures (Bortree \&Seltzer, 2009). This will bring about forge of alliance between organization and it public.

The possible challenges hampering the successful use and gratifications for banks that adopt social media platforms in facilitating adverting needs. The results show that; First Bank are face with the issue of trust, identity, believability, competent, reliability, technical knowledge and control in the use of social media.

Though social media came with a huge promise to financial institutions just at it deed for or profession also, but speed of the changes and the quest to adopt social media tools and its dynamics to organized profession such as advertising has being a challenge. Thus, the spread of unverified information, slander, deliberate falsehood, hackers and difficulty to control post a serious challenge in managing organization internal and external crisis

The speed of the changes and the quest to adopt social media tools and its dynamics to organized profession such as advertising has being a challenge. The issue of trust management, control, technical knowledge, identity management and crisis communications are problematic to the profession. Thus, unrestricted audience and irreversible information are the major challenges to banks are facing using social media to improve their professionalism practice.

One of the major challenges of advertisers using social media is the inability to have control as earlier studies have confirmed. McCorkindale and Wright (2011) studies found that the most common challenge for advertisers is the lack of control associated with social media and not knowing what people might say or do. They noted that the continues spread of unverified information, slander, deliberate falsehood, hackers which is difficult to control post a serious challenge to practitioners in managing internal and external crisis.

\section{Conclusion}

The results of these hypotheses revealed that the First Bank has embraced social media advertising in a big way. Furthermore, there is a strong link between the pattern of social media advertising and First Bank's advertising needs. It also confirms the hypothesis that First Bank social media advertising has a significant positive association with social media advertising pleasure. Exploring the use of social media advertising among Nigerian banks is vital in order to comprehend the revolutionary changes that new social media technologies have brought to the profession of advertising in Nigeria and around the world. As the number of businesses that use social media for marketing grows, evaluating how each of the numerous components of social media is used becomes more important.

As a result, First Bank now has an appealing and well-designed website as well as social media pages that have an easy-to-use interface and a high level of success. As a result, social media allows First Bank to market its products and services to a group of people. Organizations can use social media to establish a virtual presence in cyberspace as a tool to communicate their mission, products, and services to the rest of the world (Lee 2014). When it comes to information transmission and exchange, such communications platforms differ from traditional mass media in that they have the capacity for speed, efficiency, integration, and interactivity (Esrock \& Leichty, 2000). These important activities include one-to-one communication via email, one-to-many communication via websites and email, and many-to-many communication via websites, newsgroups, mailing lists, and now blogs and social networking sites like Twitter and Facebook (Avlonitis and Karayanni, 2000). This is also a benefit of First Bank's social media utilization. 
As a result, financial institutions can use social media to participate in interactive dialogue with their customers, boosting effective comprehension.

Indeed, using social media advertising as an interactive medium for dialoguing with stakeholders has been shown to be useful in the building and maintenance of successful partnerships (Waters and Tindall, 2010; Reber and Kim, 2006), and banks are no exception. Banks spend millions of dollars on both offline and online image construction and maintenance. As a result, banks must establish asynchronous communication relationships with key stakeholders such as consumers, shareholders, government officials, and workers (Branco and Rodrigues, 2006). One of the keys to addressing the information needs of these many "publics" is for banks to communicate with them properly. This is only possible if the organization has a working website that is updated on a regular basis and allows the public to comment on the organization's discussion.

\section{Limitations}

One important limitation of this study was the period of time used in gathering the data. A lengthier period would have revealed a greater depth of findings and also generated more insights leading to more reliable results which could have been generalized.

Given the time constraints of this project, only one out of 19 commercial banks in Nigeria were examined. The customers of this bank were also limited to Ilorin metropolis; a more comparative study would have provided critical insights to the perception of other customers outside Ilorin. It would have also enabled better representation and more valid generalization of the findings.

It is pertinent to state that banks have a discreet nature of not divulging sensitive information about their scale of operation. Hence, getting the total population of banks customers was difficult due to a confidentiality clause of not disclosing information regarding their bank's customer strength. And, this has serve as a limiting factor.

\section{Recommendations}

By examining the uses of social media advertising by First Bank, this study attempted to contribute to the development of the diffusion of innovation and uses and gratification communication theories in the Nigerian context. The findings of this study have invariably contributed to the cross cultural application as well as extended the dialogic potential of new communication, thus Future studies could look into the interactive and real-time medium's sustained importance for advertisers.

This report makes ideas for how bank executives might use technology to improve their client-customer relationships. One area of priority is using the internet to communicate or disclose information to stakeholders, and banks are right in the midst of it since competition in that business is severe. While developing a wellrounded internet platform that scores highly on the five principles outlined in this study may be expensive in the short term, the long-term benefits (i.e. the ability to disseminate information more cheaply and in a timely manner) make it a worthwhile venture.

The necessity for two-way communication should be considered by bank image builders. It turned out that the bank under investigation is making extensive use of social media sites as interactive advertising platforms. They just use their websites to keep their customers informed. As a result, for banks to be allowed to utilize their websites as effective advertising tools, they must meet the criteria established for interactive and control medium.

On the subject of social media issues, banks advertisers are expected to be aware of the areas that may be addressed, such as preventing unethical and anonymous individuals from accessing their platform. Furthermore, only reputable and trustworthy material should be allowed on social media.

Banks should also examine their websites on a frequent basis to ensure that updated information is supplied on a timely basis.

According to Eisenborg (2005), site improvement is a continuous process, not a one-time effort, and this study advocates online surveys, focus group talks, and hiring a full-time analyst(s) as some of the imperatives. According to Eisenberg, an increasing number of firms are discovering the value of critically examining their website/website traffic and using the information to increase their earnings. Even though Eisenberg's concept is almost a decade old, it still holds true, and advertisers would need a research staff (a full-time analyst or analysts) to create insights from website visitors for site enhancement.

\section{References}

Adeola, A.A. (2016). New media and the marketing strategies of Nigerian banks: A case study of First Bank of Nigeria Ltd. Net Journal of Social Sciences, 4(4), 70-80.

Anthony, U. \& Ogidi, O. (2016). Is the New Media Superior to Traditional Media for Advertising?Asian Journal of Economic Modelling, 4(1), 57-69

Baird, C. H. \& Parasnis, G. (2011).From social media to social customer relationship management. Strategy and Leadership, 39(5), 30-37. 
Broom, G., Casey, S. \& Ritchey, J. (2009). Toward a concept and theory of organization-public relationships: An update. In J.A. Ledingham \& S.D. Bruning (Eds.), Public relations as relationship management: $A$ relational approach to public relations (pp. 3-22). Mahwah, NJ: Lawrence Erlbaum Associates.

Bruhn, M., Schoenmueller, V. \& Schäfer, D. B. (2012). Are social media replacing traditional media in terms of brand equity creation? Management Research Review, 60(3), 770-790.

Chanda, R. \&Zaorski, S. (2013). Social media usage in the financial services industry: Toward a business-driven compliance approach. Journal of Taxation and Regulation of Financial Institutions, 28(5), 5-20.

Cho, S., \& Huh, J. (2010). Content analysis of corporate blogs as relationship management tool. Corporate Communications: An International Journal, 15(1), 30-48.

DeFleur, M. L., \& Dennis, E. E. (1994). Understanding mass communication: A liberal arts perspective. Boston: Houghton Mifflin.

Dominick, J.R. (2009). The dynamics of mass communication : Mass media in the digital age. (7th ed.). New York: McGraw Hill Companies

Ekwueme, A. (2013). Bank consolidation in Nigeria and challenges to the financial relations practitioners: An analysis. International Journal of Communication, 12(15), 252-270.

Eleboda, S.S \& Majekodunmi, B.E. (2015).Upsurge of social media advertising (SMA) in the Nigerian financial services sector: Are the youths ready? American Journal of Marketing Research, 1(2), 37-44.

Esrock, S.L.\& Leichty, G.B. (2000). Organization of corporate web pages: Publics and functions. Public Relations Review, 26, 327-44.

Folarin, B. (2005). Theories of mass communication: An introductory text. Ibadan: Stirling-Horden.

Hart, L. (2010). Social media. In J. Doorley \& H.F. Garcia (Eds.).Reputation management: Thekey to successful public relations and corporate communication (pp. 112-133.). New York,NY: Routledge.

Hayakawa, S.I., (1964). Language in thought and action. New York: Harcourt, Brace and World

Hill, L.N. \& White, C. (2000). Public relations practitioners' perception of the World Wide Web as a communications tool. Public Relations Review, 26, 31- 46.

Krejcie, R.K \& Morgan D.W. (2006). Determining sample size for research activities, education and psychological measurement. New York Academic Press. Pp.608-609

Kur, J. T. (2003). The perceptual impact of online advertising on internet users in Nsukka Town. Nsukka Journal of Mass Communication, 1(1), 31-41.

Lee, P.Y. (2014). Social media challenges for advertising business and creatives management in the social media era. International Journal of Research in Business Studies and Management, 1(1), 1-11.

Lovejoy, K., Waters, R., \& Saxton, G. (2012). Engaging stakeholders through Twitter: how non-profit organizations are getting more out of 140 characters or less. Public Relations Review, 38(2) 313-318

National Archives (2013). Effective communications: Raising the profile of your archive service. Retrieved August 24, 2019 from http://nationalarchives.gov.uk/doc/open-government-license

Nwaeze, C. (2009). The online advertising mileage. Broadstreet Journal. Edition 13, March 30.

Nyekwere, E.O, Kur, J.T. \& Nyekwere, O. (2014).Awareness and Use of Social Media in Advertising: The Case of Facebook among Residents of Port Harcourt, Nigeria. An International Multidisciplinary Journal, Ethiopia, 7 (4), 174-194.

Okaiyeto, S.A, \& Ottah, G.A. (2021). Staff Perception of the Use of Website and Social Networking Sites as Public Relations Dialogic Tools in Universities in Kogi State. UNIUYO Journal of Humanities (UUJH), 25(1), 264-290.

Oluwatolani, O., Joshua, A. \& Philip, A. (2011).The impact of information technology in Nigeria's Banking Industry. Journal of Computer Science and Engineering, 7(2), 63-67.

Porter, L.V. \& Sallot, L.M. (2005). Web power: a survey of practitioners' World Wide Web use and their perception of its effects on their decision-making power. Public Relations Review,31(1), 111-119.

Rybalko, S., \& Seltzer, T. (2010). Dialogic communication in 140 characters or less: howFortune 500 companies engage stakeholders using Twitter. Public Relations Review, 36(4), 336-341.

Veenswyk, M. (2013).Leveraging Social Media in the Banking Industry. Social Media Capture, Control, Communication and Compliance

Waters, R.D.\& Tindall, N.T. (2010) Marketing churches on the Internet: An analysis of the dialogicpotential of Christian websites. International Journal of nonprofit and voluntary sector marketing 15, 369-381.

Wimmer, R. D., \& Dommick, J. R. (2014). Mass media research: an introduction. ( $9^{\text {th }}$ ed.). Southbank, Victoria: Thomson Wadsworth. 